$\angle$ Research Square

\title{
Differential Responses of Ceratitis Capitata to Infection by the Entomopathogenic Fungus Purpureocillium Lilacinum.
}

\section{Wafa Djobbi}

National Centre of Nuclear Sciences and Technologies

Meriem Msaad Guerfali ( $\square$ msaad_tn@yahoo.fr)

National Centre of Nuclear Sciences and Technologies

Agnès Vallier

Institut National des Sciences Appliquées de Lyon

Kamel Charaabi

National Centre of Nuclear Sciences and Technologies

Justin Maire

Institut National des Sciences Appliquées de Lyon

Niclas Parisot

Institut National des Sciences Appliquées de Lyon

Hubert Charles

Institut National des Sciences Appliquées de Lyon

Haytham Hamden

National Centre of Nuclear Sciences and Technologies

Salma Fadhl

National Centre of Nuclear Sciences and Technologies

Abdelaziz Heddi

Institut National des Sciences Appliquées de Lyon

Ameur Cherif

Manouba University

\section{Research Article}

Keywords: host, entomopathogenic fungi, integrated pest management, medfly, genes

Posted Date: December 8th, 2021

DOI: https://doi.org/10.21203/rs.3.rs-1064769/v1 
License: (c) (i) This work is licensed under a Creative Commons Attribution 4.0 International License. Read Full License 


\section{Abstract}

Ceratitis capitata (medfly), is one of the most injurious pests of fruits with quarantine importance because of its extremely wide host range. The use of entomopathogenic fungi constitutes a promising approach for potential applications in integrated pest management. Nonetheless, developing methods of insect control can also involve the use of fungal machinery to produce metabolic disturbance that can increase its effectiveness by producing a detrimental effect on insect development. Insect species, such as Ceratitis capitata, depend on reproduction potential, nutrient reserves, metabolic activities and immune response for their survival. Accordingly, the purpose of this study is to use the entomopathogenic fungus Purpureocillium lilacinum to investigate, its sublethal effects on Ceratitis capitata. Laboratory bioassays were conducted on medfly V8 strain. The bioassays were monitored to determine the virulence of $P$. lilacinum on the fruit fly. P. lilacinum was tested against 5 days-old males and females, through abdominal topical applications. Following the fungal inoculation, we showed (i) a significant increase of sugar amount in tissues, (ii) a significant decrease in carbohydrase activities, digestive glycosyl hydrolase and proteinase activities in whole midguts of treated flies, (iii) an over-expression of Takeout and Attacin-A genes induced by infection. Moreover, the up-regulations observed for relish, cecropin 1, ceratotox-A and defensin genes are due to physiological mechanisms occurring during infection.

\section{Introduction}

Ceratitis capitata (medfly), is one of the most injurious pests of fruits with quarantine importance because of its extremely wide host range. The use of entomopathogenic fungi constitutes a promising approach for potential applications in integrated pest management. Nonetheless, developing methods of insect control can also involve the use of fungal machinery to produce metabolic disturbance that can increase its effectiveness by producing a detrimental effect on insect development. Insect species, such as Ceratitis capitata, depend on reproduction potential, nutrient reserves, metabolic activities and immune response for their survival. Accordingly, the purpose of this study is to use the entomopathogenic fungus Purpureocillium lilacinum to investigate, its sublethal effects on Ceratitis capitata. Laboratory bioassays were conducted on medfly V8 strain. The bioassays were monitored to determine the virulence of $P$. lilacinum on the fruit fly. P. lilacinum was tested against 5 days-old males and females, through abdominal topical applications. Following the fungal inoculation, we showed (i) a significant increase of sugar amount in tissues, (ii) a significant decrease in carbohydrase activities, digestive glycosyl hydrolase and proteinase activities in whole midguts of treated flies, (iii) an over-expression of Takeout and Attacin-A genes induced by infection. Moreover, the up-regulations observed for relish, cecropin 1, ceratotox-A and defensin genes are due to physiological mechanisms occurring during infection.

Ceratitis capitata (medfly) (Wiedemann) (Diptera: Tephritidae), is a cosmopolitan invasive agricultural pest that affects a wide host range of fruits ${ }^{1,2}$ and has a worldwide distribution ${ }^{3}$. Chemical treatments constitute the useful tool in Tunisia for the control of medfly, however repeated pesticide use exerts a specific selection pressure which is pesticide resistance 4 . Environmentally friendly control procedures were developed for the control of medfly, using microorganisms such as bacteria, fungi and viruses. Over 
the last years, the use of entomopathogenic fungi constituted a promising agent of control for insect pests in agriculture. The use of entomopathogenic fungi as biocontrol agents plays a crucial position in enhancing integrated pest management (IPM) efficiency.

Entomopathogenic fungi (EPF) have been shown to be potent biocontrol agents. Furthermore, they have been attested to induce a large scale of sublethal effects within infected insects. Accumulating evidence were reported that EPF profoundly affect host biological traits including mating behavior alteration, food consumption reduction ${ }^{5}$, immune reaction alterations ${ }^{6}$, developmental rates, longevity and fecundity reductions ${ }^{7}$. However, over time Purpureocillium lilacinum has been described mainly as nematode pathogen but also have shown clear potential as insect-pest control agent. The adult Mexican fruit fly Anastrepha ludens ${ }^{8}$, the melon fly Bactrocera cucurbitae ${ }^{9}$, the brown flour beetle Tribolium confusum ${ }^{10}$, the cotton aphid Aphis gossypii ${ }^{11}$, the cotton bollworm Helicoverpa zea ${ }^{12}$, the fruit fly Bactrocera spp. ${ }^{13}$, the greater wax moth Galleria mellonella ${ }^{14}$, the tomato moth Tuta absoluta ${ }^{15}$, the Asian citrus psyllid, Diaphorina citri ${ }^{16}$ and the Sweet potato whitefly Bemisia tabaci ${ }^{17}$.

$P$. lilacinum is a slowly killing pathogen able to survive for longer periods within hosts ${ }^{18}$. This strategy allows $P$. lilacinum to be more efficient and to have a higher transmission rate ${ }^{5,8}$. It has now been confirmed that protease, phospholipases, chitinase, mannanase, beta-glucanase and lipase hydrolyzing enzymes ${ }^{19}$, leucinostatins and paecilomide secondary metabolites ${ }^{20}$ play crucial roles in P. lilacinum pathogenicity. Many of these secondary metabolites showed immune system modulatory activity, as well as insecticidal, cytotoxic, and antimicrobial activities ${ }^{21}$.

An increasing number of studies have proven that $P$. lilacinum is negatively affecting the host's biological parameters, in addition to causing death due to mycosis ${ }^{22}$. Recent advances have revealed many effects on reproduction ${ }^{11,21}$, growth ${ }^{23}$, food consumption and sexual behavior ${ }^{24}$. Meanwhile, the mechanisms of host-fungus interaction are still understudied and poorly understood. P. lilacinum mediates various toxicological effects making it useful for control strategies. Consequently, this study is the first report on applying the fungus $P$. lilacinum as a novel and promising biocontrol agent against $C$. capitata. We have examined the role of $P$. lilacinum in transformation response elaboration within $C$. capitata. We investigated in-vitro, the sublethal activities of $P$. lilacinum and analyzed biologically susceptible activities, (i) fertility and fecundity parameters, (ii) nutrient reserves, (iii) biochemical enzymes activities, (iv) defense-related genes.

\section{Results}

Fecundity and fertility parameters. After the inoculation of the spore suspension, treated flies laid lower average of eggs per female when compared to untreated individuals. A significant reduction in fecundity and egg fertility of treated females was observed. About only $133.50 \pm 1.08$ eggs were laid by treated female, whereas control flies laid $245 \pm 4$ eggs per female (Table 1 ). In addition, P. lilacinum inoculation 
reduced significantly egg fertility by $62.9 \% ; 28.8 \pm 4.4 \%$ of the eggs hatched from treated flies compared to $91.7 \pm 2.7 \%$ from non-treated flies $\left(F_{3,2}=44.82, P<0.0005\right)$ (Table 1$)$.

Nutrient reserves measurement. Treatment with $P$. lilacinum has resulted in a varying composition of larvae nutrient reserves. The amount of sugar increased significantly $(P=0.007)$ in tissues of third instars larvae from treated flies $0.521 \pm 0.002 \mu \mathrm{g} / \mathrm{mg}$ of Protein, compared to larvae from non-treated flies 0.332 $\pm 0.001 \mu \mathrm{g} / \mathrm{mgP}$. Moreover, glycogen and lipid amounts remained the same, less than $0.05 \mu \mathrm{g} / \mathrm{mgP}$, there was no significant difference between larvae from infected and control flies (Fig. 1).

Enzymatic assays. The carbohydrase activity in the whole midguts of treated flies showed a significant decrease post-inoculation for starch $487.04 \pm 41.98 \mathrm{AU} / \mathrm{mgP}(\mathrm{P}<0,00001)$ and for Pectin $130.48 \pm 51.95$ $\mathrm{AU} / \mathrm{mgP}(\mathrm{P}=0.009)$, compared to controls $1055.68 \pm 44.29 \mathrm{AU} / \mathrm{mgP} ; 468.37 \pm 32.23 \mathrm{AU} / \mathrm{mgP}$; respectively (Fig. 2).

The digestive glycosil activity seems to be affected as well during infection. After $72 \mathrm{~h}$ of fungal inoculation, treated flies showed a significant decrease in specific a-glucosidase activity $18.43 \pm 0.14$ AU/Gut compared to control flies $24.53 \pm 0.955 \mathrm{AU} / \mathrm{Gut}(\mathrm{P}=0.0001)$ and in $\beta$-galactosidase activity $9.10 \pm$ $0.75 \mathrm{AU} /$ Gut, compared to control flies; $16.33 \pm 1.24 \mathrm{AU} / \mathrm{Gut}(\mathrm{P}<0.0001)$ (Fig. 3).

The digestive proteinases (measured by the amounts of azocasein and hemoglobin in the midgut) are less active in infected adults of $C$. capitata than controls. Higher capacity to digest protein for control flies midgut was observed. For azocaseinase and hemoglobinase, infection induced a significant decrease $(P=0.0001 ; P=0.003$, respectively) in activity $2 \pm 0.2 \mathrm{AU} / \mathrm{Gut}$, and $5.66 \pm 2.11 \mathrm{AU} / \mathrm{Gut}$, respectively compared to controls $4.93 \pm 0.58 \mathrm{AU} /$ Gut; $13.64 \pm 0.50 \mathrm{AU} /$ Gut; respectively (Fig. 4).

Molecular assays: steady-state levels of gene transcripts. Box-plots (Fig. 5) revealed that the expression profile of some AMPs encoding genes depends significantly on fly gender for both infected and control flies. The sex seems to strongly influence the expression of AMPs regardless of the infection status. A significant change in expression levels of $\operatorname{Attacin}-A(\mathrm{~F}=19.06 ; \mathrm{P}=0.001)$, Ceratotoxin- $A(\mathrm{~F}=3.76 ; \mathrm{P}=0.05)$, and Takeout $(\mathrm{F}=4.66 ; \mathrm{P}=0.001)$ within females rather than males was observed.

The variable status (Virgin, mature and mated) influenced the expression profile of some AMP encoding genes (Fig. 6). We noticed a significant activation of immune-response related genes: Attacin- $A(\mathrm{~F}=$ $19.06, \mathrm{P}<0.001)$, Takeout $(\mathrm{F}=4.66, \mathrm{P}=0.05)$, Ceratotoxin- $A(\mathrm{~F}=3.76, \mathrm{P}=0.01)$, and the IMD pathway transcription factor Relish ( $\mathrm{F}=12.85, \mathrm{P}<0.001)$ for both sexes. For females (Fig. $6 \mathrm{~B})$, the expression profile of Attacin-A and Ceratotoxin-A increases with maturity compared to their counterparts virgin, immatures, and mated flies. Males showed a profile that remains similar to that expressed by females (Fig. 6A). Mature males express more AMPs than virgin immature and mated ones.

Times after infection induce a significant increase on 5 of the 7 transcripts studied: $A t t a c i n-A(F=11.76$, $\mathrm{P}<0.001)$, Ceratotoxin $-A(\mathrm{~F}=6.44, \mathrm{P}<0.001)$, Takeout $(\mathrm{F}=11.33, \mathrm{P}<0.001)$, Defensin $(\mathrm{F}=4.21, \mathrm{P}=0.01)$, 
and Relish $(\mathrm{F}=15.44, \mathrm{P}<0.001)$ for both males and females infected, compared to uninfected flies (Fig. 7).

After $72 \mathrm{~h}$ of inoculation, infection variable modulated significantly Attacin-A $(\mathrm{F}=6.49, \mathrm{P}=0.01)$, and Takeout $(\mathrm{F}=13.01 ; \mathrm{P}<0.001)$ expression levels for the times analyzed $(0 \mathrm{~h}, 24 \mathrm{~h}, 72 \mathrm{~h}$ and $144 \mathrm{~h})$. For the other examined genes: Defensin, Relish, PGRP-LC, Ceratotoxin-A, and Cecropin-1, there was no significant evidence for specific changes on expression levels after the fungal inoculation (Fig. 8). For Virgin flies profile, a significant increase on transcript levels of Takeout $\left(\mathrm{F}_{15,32}=7.12 ; \mathrm{P}<0.005\right)$, and Attacin-A $\left(\mathrm{F}_{15,32}\right.$ $=2.1 ; \mathrm{P}=0.05$ ) was observed by 3.56 -fold and 6.68 -fold; respectively with infected females (Fig. $8 \mathrm{~B}$ ), and by 9.26 -fold and 1.13-fold, respectively with infected males (Fig. 8A).

A Significant status $x$ time interaction $(F=3.13 ; P=0.007)$, and sex $x$ status $x$ infection $(F=7.04 P=0.001)$ were obtained as well with the transcriptional activity of Cecropin- $1\left(F_{15,32}=3.66 ; P<0.001\right)$ by 52.80 -fold and 9.90-fold within males and females, respectively (Fig. 8).

After maturation, a transcriptional activity of immune-response-related genes was observed for both males and females inoculated with $P$. lilacinum in comparison to their counterpart control flies. A significant overexpression of Attacin-A $\left(\mathrm{F}_{15,32}=2.17 ; \mathrm{P}=0.03\right)$ by 3.17 -fold for males, and 1.80 -fold for females was detected. Likewise, significant status $x$ sex $x$ time variables interaction $\left(F_{6,6}=2.71 ; P=0.01\right)$ was obtained with Ceratotoxin- $A\left(F_{15,32}=4.24 ; P<0.001\right)$ for infected females (Fig. 8).

Once mated, infected flies profile shows that immune response transcript levels increase by 1.80 -fold within males and by 7.50 -fold within females for Attacin- $A\left(F_{15,32}=8.54 ; P<0.005\right)$, and by 2.41 -fold within males and 39.38-fold within females for Takeout $\left(F_{15,32}=4.72\right.$; $\left.P<0.005\right)$ (Fig. 8). Moreover, the significant upregulation observed within Relish, Ceratotoxin-A, and Cecropin-1 genes after $72 \mathrm{~h}$ postinoculation are due to the time, sex, infection and status different interactions (Table 2).

\section{Discussion}

The purpose of this study was to identify biological processes by which $C$. capitata attempted to defend itself against $P$. lilacinum infection challenge. The host-pathogen interaction involved defense mechanisms which may include subsequent behavioral and/or physiological responses of the host to fungal pathogenesis. For this reason, we screened reproductive-based response (fecundity and fertility parameters), metabolic-based response (enzymatic activities), and molecular-based response (transcriptional profiles) of $C$. capitata. The expression approach to determine the effects of infection on transcript abundance in $C$. capitata focused on differentially represented transcripts related to immune system processes. Accordingly, qRT-PCR analyses were performed on infected and control virgin immature, virgin mature, and mated individuals of both sexes in order to determine whether genes related to the immune response show changes in transcriptional regardless gender (males or females) and sexual status (maturation and mating). 
P. lilacinum expresses a broad range of sublethal effects. The results showed that female progeny production and egg fertility are affected by infection with $P$. lilacinum isolate. Our findings are in pars with those demonstrated by Toledo-Hernández et al. ${ }^{8}$ who worked on the evaluation of the virulence and sublethal effects of $P$. Iilacinum against the Mexican fruit fly Anastrepha ludens. Similar effects on $C$. capitata were obtained after infection with the fungus: Beauveria bassiana, Metarhizium anisopliae, and Paecilomyces fumosoroseus ${ }^{25,26,27}$. In addition, we demonstrated the increase in sugar reserves during the third larvae instars of all sampled larvae from infected flies compared to similar low lipids and glycogen levels. In fact, insects metamorphic processes require the consumption of their carbohydrate reserves for the synthesis of pupal cuticle and imaginal tissues ${ }^{28}$. This suggests that the high sugar content can be related to a lack of energy expenditure or to a deficiency in sugar digestion machinery (inhibition of the assimilation of sugars). This hypothesis, however, needs further investigation.

Additionally, enzymatic activities from $C$. capitata adults were significantly susceptible to infection under the in vitro assays (optimum $\mathrm{pH}$ ). Ceratitis capitata rely on specific $\mathrm{\alpha}$ - and $\beta$-galactosidases associated with enzymatic activities on maltose and sucrose to digest carbohydrates with complex proteolytic systems for protein digestion, especially the serine endoproteinase ${ }^{29}$. We were able to demonstrate that the capacity to digest carbohydrates, evaluated by the amounts of di and polysaccharide in midguts, seems to be disturbed by infection. Treated flies always show a significant decrease in their enzymatic activities, compared to untreated flies, by the third day of infection. These findings are in agreement with those of Malaikozhundan and Vinodhini ${ }^{30}$ obtained with the cowpea weevil Callosobruchus maculatus infected with Bacillus thuringiensis and therefore suggest the susceptibility of $C$. capitata enzymes to $P$. lilacinum.

Sugars and proteins are macronutrients that play critical physiological roles in diptera resource allocation, longevity ${ }^{31}$, reproduction ${ }^{32}, 33$, larval development ${ }^{34}$, mating success ${ }^{35}$, and in sex pheromone production ${ }^{36,37}$. Digestion and absorption of carbohydrates stimulate the lipogenic activity (incorporation of lipid reserves). Lipids modulate hormonal changes such as juvenile hormone (JH) ${ }^{38}$ which regulates mature sexual behavior in both males and females of diverse insect orders ${ }^{39}$. In addition, it has been proven that the egg-laying abilities of laboratory reared females of the Mediterranean fruit fly Ceratitis capitata (Wiedmann) and the melon fly Bactrocera cucurbitae (Coquillett) are delayed or suppressed by limiting access to host fruits and dietary protein ${ }^{40}$. To compensate these nutritional deficiencies, adults of $C$. capitata are able to allocate energetic reserves to be used slowly under a "reproductive waiting mode" 41 or/and to proceed to egg-reabsorption in reproductive females observed in the olive fly Bactrocera oleae ${ }^{33}$. Based on these results, we can thus suggest that the low carbohydrate digestion (after enzymatic inhibition) caused by infection with $P$. lilacinum, is linked to the fertility and fecundity reduction in C. capitata.

Immune system is a key barrier against infectious microorganisms (virus, bacteria, fungi and parasites). Therefore, nutrition is essential to pathogens resistance in insects $42,43,44$. Gomulski et al. ${ }^{45}$, suggested that the abundance of immune gene transcripts might be related to the nature of the food sources within 
C. capitata. In our case, the apparent lack of immune response after fungal inoculation in $C$. capitata within some of the studied genes could, however, be related to the enzymatic activities decrease in inoculated flies. Additionally, fungi are known to produce secondary metabolites that display various immunosuppressive properties capable to disrupt the host's physiological processes ${ }^{46}$. Several fungi have proven the potential to modulate the immune response of different insects as the large pine weevil, Hylobius abietis ${ }^{47}$, the greater wax moth, Galleria mellonella ${ }^{48}$, and the tobacco caterpillar, Spodoptera litura ${ }^{49}$. P. lilacinum is known to produce leucinostatins, a family of lipopeptide antibiotics with a broad range of biological activities, including mortality and reproduction inhibition in nematodes ${ }^{21}$. These results drew our attention to the relationships between the lack of immune gene expression and leucinostatins. We hypothesize that $P$. lilacinum uses leucinostatins as immune system inhibitors to maximize its proliferation rate.

Physiological attributes (e.g., sex, maturation, mating) impact the immune system function of $C$. capitata ${ }^{45}$. The up-regulation observed with Relish, Cecropin-1, Ceratotoxin-A, and Defensin genes is probably in case of being implicated in other physiological mechanisms occurring during the same time of infection, rather than the proper effect of infection. The effect of sex (gender) and status (virgin, mature and mated) variables seems to strongly influence the expression of some $C$. capitata AMP genes regardless of the infection challenge. Females and males express different profiles levels of Attacin-A, Ceratotoxin-A, Relish, and Defensin. This sex-specific response was demonstrated previously with $C$. capitata and Drosophila suzukii ${ }^{50,51}$ During maturation, $C$. capitata expressed a significant increase in immune-response related genes (Attacin-A, Ceratotoxin-A, Relish, and Defensin) compared to their counterparts immature virgin. This up-regulation may be explained by the process of immunity anticipation prior to mating which was previously demonstrated in Ceratitis capitata ${ }^{45}$.

Following fungal inoculation, the immune system of $C$. capitata involved the activity of Takeout and Attacin- $A$ genes displayed to overcome the fungal infection within virgin immature, virgin mature, and mated flies. Accordingly, Attacin-A is an antimicrobial peptide implicated in the Imd signalization pathway 52 , and Takeout is a circadian clock-regulated output gene involved in the control of different aspects of insect behavior and physiology such as aging, longevity, feeding behavior ${ }^{53}, 54$, locomotion ${ }^{54}$, circadian behavior ${ }^{55,56}$, and insecticide susceptibility ${ }^{57,58}$. This finding provides a first evidence for the involvement of Takeout gene in C. capitata immune response against entomopathogenic fungi.

The effects cited above, in our opinion, may lie beneath the remarkable effect caused by P. lilacinum. A cause-and-effect relationship could be established between the fungal inoculation and the resulting metabolic and molecular disorders. These findings provide a comprehensive insight on the dynamics of C. capitata's response to $P$. lilacinum infection revealing that metabolic processes, rather than immune functions, played a key role in the response. Furthermore, metabolic and molecular information about $C$. capitata's response systems to $P$. lilacinum proliferation, of which little is known to date, could lead to a better understanding of the mechanism in controlling plant pests, as well as improve its capabilities as a bio-control agent. 


\section{Methods}

Flies. The Mediterranean fruit flies used in the experiments were from a colony of the VIENNA 8 (V8) genetic sexing strain (GSS) maintained in the Tunisian Medfly rearing facility situated in the National Centre of Nuclear Sciences and Technology (CNSTN). This strain has two mutations with two markers: white pupae (wp) and temperature-sensitive lethal mutation ( $t s l)$. The mass-rearing was maintained under optimal conditions ${ }^{59,60}$. Wild flies were obtained after sampling infested fruits hosting the fly. The fruits were then collected and placed on a mesh screen in a plastic container, allowing larvae to emerge from the fruit and pupate at room temperature. The pupae collected in this way are placed in bottles for the emergence of adults, which will then be used for bioassays.

Fungal isolate. .Purpureocilium lilacinum was isolated from soil samples collected from a citrus orchard in Tunisia.

Bioassays. Laboratory bioassays were conducted on medfly V8. The bioassays were monitored to determine the virulence of $P$. lilacinum on fruit fly. P. lilacinum was tested against 5 days-old males and females, through abdominal topical applications. The bioassays were carried out with five replicates under optimal conditions $20 \pm 2{ }^{\circ} \mathrm{C}, 50-60 \% \mathrm{RH}$ with a photoperiod of 15:9 (L:D) h. Fifteen adults (males and females) were individually treated with $5 \mu$ of designated suspensions and placed together in a ventilated Petri dish (89 mm diameter, $23 \mathrm{~mm}$ height). Adult flies were fed with sugar: yeast (3:1) and water. Control flies were treated with Tween $80(0.02 \%)$ free of fungal suspension.

Fecundity and fertility parameters. Adult fecundity was measured to evaluate the effect of medfly adult exposure to $P$. lilacinum treatment at $10^{8}$ conidia/ml. Each replication consists of a group of five females and five males placed in a ventilated box under optimal conditions $20 \pm 2{ }^{\circ} \mathrm{C}, 50-60 \% \mathrm{RH}$ with a photoperiod of 15:9 (L:D) h and flies were fed with sugar: yeast (3:1) and water. The combinations studied are: $\nabla$ control $X \otimes$ control; $\nabla$ treated $X \otimes$ treated. Eggs are collected 48 hours after the first day of treatment. The number of eggs laid per replication was then counted ${ }^{27}$.

Egg fertility was realized by lining up one hundred eggs in a Petri dish. Petri dishes are then incubated at $26^{\circ} \mathrm{C}$ with $60 \% \mathrm{RH}$ and a photoperiod of $16: 8$ (L: D) $\mathrm{h}$ for $48 \mathrm{~h}$. The number of larvae hatched was counted for 7 days ${ }^{27}$.

Nutrient reserves measurement. For the measurement of larvae nutrient reserves, three third-instar larvae were homogenized in $0.2 \mathrm{ml}$ of $2 \% \mathrm{Na}_{2} \mathrm{SO}_{4}$ with the addition of $1.3 \mathrm{ml}$ chloroform-methanol (1:2) (vol: vol) solution. After $10 \mathrm{~min}$ of centrifugation at $5,200 \mathrm{~g}$, the supernatant was used for lipid quantification and the pellet, was further treated for glycogen and sugars estimation ${ }^{33}$. Lipid quantification was assayed as described previously by Warburg and Yuval ${ }^{61}$. After Chloroform: methanol (1:2) total evaporation at $90^{\circ} \mathrm{C}$, lipids were resuspended in $0.3 \mathrm{ml} \mathrm{H}_{2} \mathrm{SO}_{4}$. Lipids were hydrolyzed at $90{ }^{\circ} \mathrm{C}$ for $10 \mathrm{~min}$ and an aliquot $(30 \mu \mathrm{l})$ was reacted with the $270 \mu \mathrm{l}$ vanillin reagent for $30 \mathrm{~min}$ at room temperature. Quantity of total lipids was estimated by measuring absorbance at $490 \mathrm{~nm}$ and using a vegetable oil as a 
standard. Carbohydrates content was estimated using the method in Warburg and Yuval ${ }^{61}$. After the addition of $200 \mathrm{~mL}$ of anthrone reagent and $1 \mathrm{~mL}$ of water to $300 \mu$ of the supernatant obtained from Chloroform: methanol extraction, the mixture was kept reacting for $10 \mathrm{~min}$ at $90^{\circ} \mathrm{C}$. Total carbohydrates in the sample were estimated by measuring the absorbance at $630 \mathrm{~nm}$ and using anhydrous glucose as a standard. Glycogen quantification was carried out according to Tolmasky and Krisman ${ }^{62}$. The pellet obtained was digested with $33 \% \mathrm{KOH}$ for $15 \mathrm{~min}$ followed by ethanol $96 \%$ precipitation. After overnight incubation at $4{ }^{\circ} \mathrm{C}$, glycogen was precipitated at 2,000 g and the pellet obtained was resuspended in 0.1 $\mathrm{ml}$ of water. The total amount of glycogen was then determined by the addition of $\mathrm{I}_{2} / \mathrm{Kl} / \mathrm{CaCl}_{2}$ reagent.

Enzymatic assays. Assays were realized after digestive tract dissection of 50 adult flies in $\mathrm{NaCl}(0.15 \mathrm{M})$. The intestines are then homogenized in $50 \mathrm{mM}$ Tris-HCl buffer ( $\mathrm{pH}$ 8.0). After centrifugation at 10,000 g for 30 min at $4{ }^{\circ} \mathrm{C}$, the supernatant obtained was recovered and kept at $-20^{\circ} \mathrm{C}$ to be used as a source of enzymes $^{29}$.

Disaccharide and polysaccharide activity was determined according to Baker et al. ${ }^{63}$. Briefly, $80 \mu \mathrm{l}$ of intestinal homogenates were incubated $30 \mathrm{~min}$ at $37^{\circ} \mathrm{C}$ with $60 \mu \mathrm{l}$ of $1 \%$ substrate solutions (maltose, sucrose, pectin and starch) and $400 \mu \mathrm{l}$ of sodium acetate buffer $0.1 \mathrm{M}(\mathrm{pH}=5.5)$. The aliquots were heated in boiling water for $10 \mathrm{~min}$ then $100 \mu \mathrm{l}$ of DNS solution was added. The absorbance was measured at $540 \mathrm{~nm}$. One activity unit (AU) was defined as the amount of enzyme activity that increased absorbance by 0.01 at $540 \mathrm{~nm}$. Monosaccharide activity was determined by the estimation of $\mathrm{p}$ nitrophenol (PNP) released by hydrolysis of the corresponding p-nitrophenyl conjugates used as substrates: PNP a-glu and PNP $\beta$-gal dissolved in sodium acetate buffer $0.1 \mathrm{M}, \mathrm{pH}=5.5^{29}$. The substrate solution $3 \mathrm{mM}(3 \mu \mathrm{l})$ was incubated with $50 \mu \mathrm{l}$ of the intestinal homogenates and $450 \mu \mathrm{l}$ of sodium acetate buffer at $37^{\circ} \mathrm{C}$ for 10 minutes. The reaction was stopped by the addition of $130 \mu$ of acetic acid $(30 \%, p / v)$. The amount of nitrophenol released was estimated by measuring the absorbance at $405 \mathrm{~nm}$. One activity unit (AU) was defined as the amount of enzyme activity that increased absorbance by 0.01 at $405 \mathrm{~nm}$.

Azocaseinase activity was determined according to Silva et al. ${ }^{29}$. Briefly, aliquots of $50 \mu$ l of intestinal homogenate were incubated with $450 \mu \mathrm{l}$ of buffer solution ( $50 \mathrm{mM}$ Tris- $\mathrm{HCl}, 20 \mathrm{mM} \mathrm{CaCl}, \mathrm{pH}$ 8.0) and $500 \mu \mathrm{l}$ of azocasein solution $(1.5 \%)$ at $37^{\circ} \mathrm{C}$ for $30 \mathrm{~min}$. To stop reaction, $150 \mu \mathrm{l}$ of TCA solution (20\%) was added. The samples were centrifuged at $10,000 \mathrm{~g}$ for $10 \mathrm{~min}$. The obtained supernatant was alkalinized with $\mathrm{NaOH}(0.2 \mathrm{~N})$. Soluble peptides were measured by absorbance at $440 \mathrm{~nm}$. One activity unit (AU) was defined as the amount of enzyme activity that increased absorbance by 0.01 at $440 \mathrm{~nm}$. Hemoglobinase activity was performed as described in Silva et al., ${ }^{29}$. Intestinal homogenates $(100 \mu \mathrm{l})$ were incubated with $50 \mu$ sodium acetate buffer solution ( $0.2 \mathrm{M}, \mathrm{pH} 4.5)$ and hemoglobin solution (1\%) at $37^{\circ} \mathrm{C}$ for $60 \mathrm{~min}$ and then we added $100 \mu \mathrm{l}$ of a TCA solution (40\%). Samples were centrifuged at $10,000 \mathrm{~g}$ for $10 \mathrm{~min}$ and the recovered supernatant was alkalinized with $\mathrm{NaOH}(2 \mathrm{~N})$ solution. Soluble peptides were then measured according to Lowry ${ }^{64}$ at $750 \mathrm{~nm}$. One activity unit (AU) was defined as the amount of enzyme activity that increased absorbance by 0.01 at $750 \mathrm{~nm}$. All enzymatic assays were 
performed in triplicate. Gut homogenate was replaced by saline solution for blank and gut activities were expressed as activity units per gut (AU/gut).

Molecular assays. RNA extraction was performed using trizol reagent (Invitrogen) following the manufacturer's procedures. RNA concentration and purity were assessed at 260 and $280 \mathrm{~nm}$ absorbance using a Nanodrop ${ }^{\circledR}$ spectrophotometer (Thermo Scientific). Total RNA $(1 \mu \mathrm{g})$ was treated using the RQ1RNase -Free DNase kit (Promega). Purification of the RNA was subsequently performed using the Nucleospin RNA Clean-up kit (MACHEREY-NAGEL). The synthesis of the cDNA was carried out with the Kit iScriptTM cDNA Synthesis (Bio-Rad) using $1 \mu \mathrm{g}$ of RNA in $20 \mu \mathrm{l}$ of reaction volume. The reaction program comprises a primer hybridization step (oligo (dT) and random) at $25^{\circ} \mathrm{C}$ for $5 \mathrm{~min}$, a second RT step at $46{ }^{\circ} \mathrm{C}$ for 20 min and finally inactivation of the reaction at $95^{\circ} \mathrm{C}$ for $1 \mathrm{~min}$.

Quantitative Real-Time PCR (qRT-PCR) analysis was performed to identify transcript changes in response to infection of selected genes, using cDNA derived from total RNA of flies samples. Five genes encoding antimicrobial peptides (AMPs), namely Ceratotoxin-A, Attacin-A, Cecropin-1, Takeout, Defensin, and two additional immune genes, namely Relish and $P G R P-L C$, were analyzed, as well as two reference genes, namely Gapdh and G6pdh, for the normalization (Table S1). Conventional PCR reactions were first performed for the preparation of the standard ranges (making the standard curve). The PCR products were subsequently purified using the GenElute TM PCR Clean-Up Kit (Sigma-Aldrich). The real-time quantification was performed in a CFX Connect TM Real Time System (Bio-Rad) using the MasterCycler ${ }^{\circledR}$ 480 SYBR Master I Master (ROCHE). Cycling conditions involved an initial $95^{\circ} \mathrm{C}$ for three minutes, 40 cycles of 10 seconds at $95^{\circ} \mathrm{C}, 30$ seconds at $57^{\circ} \mathrm{C}$ and 30 seconds at $68^{\circ} \mathrm{C}$. A fluorescence reading was made at the end of each extension step. Three replicates were performed and specificity of the amplification products was assessed by melt-curve analysis. The standard curves were constructed with serial 6-fold dilutions for each AMP genes studied, ranging from $2000 \mathrm{fg} / \mu \mathrm{l}$ to $0.2 \mathrm{fg} / \mu \mathrm{l}$. PCR efficiencies were above $94 \%$ for all primer pairs (Table S1). A fluorescence reading was performed at the end of each step of extension.

Statistical analysis. All the parameters were statistically processed by analysis of variance with a singlefactor ANOVA test followed by Dunnett test. Results are reported as means \pm standard error (SE). To determine the significant enrichment of differentially expressed immune related genes, analysis was performed using multi-way Analysis of Variance (ANOVA). Furthermore, to identify variables effects (sex, maturity and mating) on immune response of Ceratitis capitata V8, R programming language was used to reveal interaction between Status, Sex, Time and Infection factors.

\section{Declarations}

Acknowledgments: We thank all members of the Medfly rearing facility for their technical support. This work was supported by a grant from the Ministry of higher education and scientific research under the PRIMA project INTOMED. PRIMA is supported under Horizon 2020, the European Union's Framework Programme for Research and Innovation. 
Author Contributions: Conceptualization, Meriem Msaad Guerfali and Wafa Djobbi; Methodology,Wafa Djobbi; Meriem Msaad Guerfali, Agnès Vallier; Kamel Charaabi; Haytham Hamden and Salma Fadhl, software, Justin Maire; Nicolas Parisot; validation, Aziz Heddi; Meriem Msaad Guerfali; Hubert Charles and Ameur Cherif; writing-original draft preparation, Wafa Djobbi; writing-review and editing, Meriem Msaad Guerfali, Ameur Cherif and Aziz Heddi; visualization, Nicolas Parisot; supervision, Ameur Cherif; project administration, Meriem Msaad Guerfali; funding acquisition, Meriem Msaad Guerfali. All authors have read and agreed to the published version of the manuscript.

Conflicts of Interest: The authors declare no conflict of interest. The funders had no role in the design of the study; in the collection, analyses, or interpretation of data; in the writing of the manuscript, or in the decision to publish the results".

\section{References}

1. Malacrida, A. R., Gomulski, L. M., Bonizzoni, M., Bertin, S., Gasperi, G., \& Guglielmino, C. A. Globalization and fruitfly invasion and expansion: the medfly paradigm. Genetica, 131(1), 1-9 (2007).

2. Liquido, N. J., Barr, P. G., \& Cunningham, R. T. MEDHOST, an encyclopedic bibliography of the host plants of the Mediterranean fruit fly, Ceratitis capitata (Wiedemann), version 1. Fruit fly expert identification system and systematic information database, Diptera dissemination disk, 1(2013).

3. De Meyer, M., Robertson, M. P., Peterson, A. T., \& Mansell, M. W. Ecological niches and potential geographical distributions of Mediterranean fruit fly (Ceratitis capitata) and Natal fruit fly (Ceratitis rosa). Journal of Biogeography, 35(2), 270-281 (2008).

4. Magaña, C., Hernández-Crespo, P., Ortego, F., \& Castañera, P. Resistance to malathion in field populations of Ceratitis capitata. Journal of Economic Entomology, 100(6), 1836-1843 (2007).

5. Toledo, J., Campos, S. E., Flores, S., Liedo, P., Barrera, J. F., Villaseñor, A., \& Montoya, P. Horizontal transmission of Beauveria bassiana in Anastrepha ludens (Diptera: Tephritidae) under laboratory and field cage conditions. Journal of economic entomology, 100(2), 291-297 (2014).

6. Kryukov, V. Y., Rotskaya, U., Yaroslavtseva, O., Polenogova, O., Kryukova, N., Akhanaev, Y., ... \& Glupov, V. V. Fungus Metarhizium robertsii and neurotoxic insecticide affect gut immunity and microbiota in Colorado potato beetles. Scientific reports, 11(1), 1-13 (2021).

7. Liu, J. F., Zhang, Z. Q., Beggs, J. R., Paderes, E., Zou, X., \& Wei, X. Y. Lethal and sublethal effects of entomopathogenic fungi on tomato/potato psyllid, Bactericera cockerelli (Šulc)(Hemiptera: Triozidae) in Capsicum. Crop Protection, 129, 105023 (2020).

8. Toledo-Hernández, R. A., Toledo, J., Valle-Mora, J., Holguín-Meléndez, F., Liedo, P., \& Huerta-Palacios, G. Pathogenicity and virulence of Purpureocillium lilacinum (Hypocreales: Ophiocordycipitaceae) on Mexican fruit fly adults. The Florida Entomologist, 102(2), 309-314 (2019).

9. Amala, U., Jiji, T., \& Naseema, A. Laboratory evaluation of local isolate of entomopathogenic fungus, Thom Samson (ITCC 6064) against adults of melon fruit fly, Bactrocera cucurbitae Coquillett. Journal of Tropical Agriculture, Paecilomyces lilacinus 51(1), 132-134(2013). 
10. Barra, P., Etcheverry, M., \& Nesci, A. Efficacy of 2, 6-di (t-butyl)-p-cresol (BHT) and the entomopathogenic fungus Purpureocillium lilacinum, to control Tribolium confusum and to reduce aflatoxin B1 in stored maize. Journal of Stored Products Research, 64, $72-79$ (2015).

11. Castillo Lopez, D., Zhu-Salzman, K., Ek-Ramos, M. J., \& Sword, G. A. The entomopathogenic fungal endophytes Purpureocillium lilacinum (formerly Paecilomyces lilacinus) and Beauveria bassiana negatively affect cotton aphid reproduction under both greenhouse and field conditions. PloS one, 9(8), e103891 (2014).

12. Lopez, D. C., \& Sword, G. A. The endophytic fungal entomopathogens Beauveria bassiana and Purpureocillium lilacinum enhance the growth of cultivated cotton (Gossypium hirsutum) and negatively affect survival of the cotton bollworm (Helicoverpa zea). Biological Control, 89, 53-60 (2015).

13. Mar, T. T., \& Lumyong, S. Evaluation of effective entomopathogenic fungi to fruit fly pupa, Bactrocera spp. and their antimicrobial activity. Chiang Mai Journal of Science, 39(3), 464-477 (2012).

14. Demirci, S. N. Ş., \& Altuntaş, H. Entomopathogenic potential of Purpureocillium lilacinum against the model insect Galleria mellonella (Lepidoptera: Pyralidae). Environmental and Experimental Biology, 17(2), 71-74 (2019).

15. Yüksel, E., Açıkgöz, Ç., Demirci, F., \& Muștu, M. Effects of the entomopathogenic fungi, Beauveria bassiana, Isaria farinosa and Purpureocillium lilacinum, on eggs of Tuta absoluta (Meyrick) (Lepidoptera: Gelechiidae). Türkiye Biyolojik Mücadele Dergisi, 8(1), 39-47 (2017).

16. Du, D., Lu, L., Hu, X., Pu, Z., Huang, Z., Chen, G., ... \& Lyu, J. Virulence of Purpureocillium lilacinum strain ZJPL08 and efficacy of a wettable powder formulation against the Asian citrus psyllid (Diaphorina citri). Biotechnology \& Biotechnological Equipment, 34(1), 1104-1113 (2020).

17. Sun, T., Wu, J., \& Ali, S. Morphological and molecular identification of four Purpureocillium isolates and evaluating their efficacy against the sweet potato whitefly, Bemisia tabaci (Genn.)(Hemiptera: Aleyrodidae). Egyptian Journal of Biological Pest Control, 31(1), 1-9 (2021).

18. Roy, H. E., Steinkraus, D. C., Eilenberg, J., Hajek, A. E., \& Pell, J. K. Bizarre interactions and endgames: entomopathogenic fungi and their arthropod hosts. Annu. Rev. Entomol., 51, 331-357 (2006).

19. Bonants, P. J., Fitters, P. F., Thijs, H., den Belder, E., Waalwijk, C., \& Henfling, J. W. D. A basic serine protease from Paecilomyces lilacinus with biological activity against Meloidogyne hapla eggs. Microbiology, 141(4), 775-784 (1995).

20. Teles, A. P. C., \& Takahashi, J. A. Paecilomide, a new acetylcholinesterase inhibitor from Paecilomyces lilacinus. Microbiological research, 168(4), 204-210 (2013).

21. Wang, G., Liu, Z., Lin, R., Li, E., Mao, Z., Ling, J., ... \& Xie, B. Biosynthesis of antibiotic leucinostatins in bio-control fungus Purpureocillium lilacinum and their inhibition on Phytophthora revealed by genome mining. PLoS pathogens, 12(7), e1005685 (2016).

22. Jessica, J. J., Peng, T. L., Sajap, A. S., Lee, S. H., \& Syazwan, S. A. Evaluation of the virulence of entomopathogenic fungus, Isaria fumosorosea isolates against subterranean termites Coptotermes spp.(Isoptera: Rhinotermitidae). Journal of Forestry Research, 30(1), 213-218 (2019). 
23. Hunter, W. B., Avery, P. B., Pick, D., \& Powell, C. A. Broad spectrum potential of Isaria fumosorosea against insect pests of citrus. Florida Entomologist, 94(4), 1051-1054 (2011).

24. Toledo-Hernández, R., Toledo, J., Liedo, P., Holguín-Meléndez, F., Valle-Mora, J., \& Huerta-Palacios, G. Effects of Purpureocillium lilacinum (Hypocreales: Ophiocordycipitaceae) on food consumption and sexual behavior of Anastrepha ludens (Diptera: Tephritidae) fruit flies. International Journal of Tropical Insect Science, 1-8 (2021).

25. Castillo, M. A., Moya, P., Hernández, E., \& Primo-Yufera, E. Susceptibility of Ceratitis capitata Wiedemann (Diptera: Tephritidae) to entomopathogenic fungi and their extracts. Biological control, 19(3), 274-282 (2000).

26. Dimbi, S., Maniania, N. K., Lux, S. A., Ekesi, S., \& Mueke, J. K. Pathogenicity of Metarhizium anisopliae (Metsch.) Sorokin and Beauveria bassiana (Balsamo) Vuillemin, to three adult fruit fly species: Ceratitis capitata (Weidemann), C. rosa var. fasciventris Karsch and C. cosyra (Walker)(Diptera: Tephritidae). Mycopathologia, 156(4), 375-382 (2003).

27. Quesada-Moraga, E., Ruiz-García, A., \& Santiago-Alvarez, C. Laboratory evaluation of entomopathogenic fungi Beauveria bassiana and Metarhizium anisopliae against puparia and adults of Ceratitis capitata (Diptera: Tephritidae). Journal of Economic Entomology, 99(6), 19551966 (2006).

28. Tolmasky, D. S., Rabossi, A., \& Quesada-Allué, L. A. Synthesis and mobilization of glycogen during metamorphosis of the medfly Ceratitis capitata. Archives of Biochemistry and Biophysics, 392(1), 3847 (2001).

29. Silva, F. C., Alcazar, A., Macedo, L. L., Oliveira, A. S., Macedo, F. P., Abreu, L. R., ... \& Sales, M. P. Digestive enzymes during development of Ceratitis capitata (Diptera: Tephritidae) and effects of SBTI on its digestive serine proteinase targets. Insect Biochemistry and Molecular Biology, 36(7), 561-569 (2006).

30. Malaikozhundan, B., \& Vinodhini, J. Biological control of the Pulse beetle, Callosobruchus maculatus in stored grains using the entomopathogenic bacteria, Bacillus thuringiensis. Microbial pathogenesis, $114,139-146$ (2018).

31. De Lacerda, J. T. J. G., e Lacerda, R. R., Assuncao, N. A., Tashima, A. K., Juliano, M. A., dos Santos Jr, G. A., ... \& Santi-Gadelha, T. New insights into lectin from Abelmoschus esculentus seeds as a Kunitztype inhibitor and its toxic effects on Ceratitis capitata and root-knot nematodes Meloidogyne spp.

Process Biochemistry, 63, 96-104 (2017).

32. Jensen, K., McClure, C., Priest, N. K., \& Hunt, J. Sex-specific effects of protein and carbohydrate intake on reproduction but not lifespan in Drosophila melanogaster. Aging cell, 14(4), 605-615 (2015).

33. Nestel, D., Tolmasky, D., Rabossi, A., \& Quesada-Allué, L. A. Lipid, carbohydrates and protein patterns during metamorphosis of the Mediterranean fruit fly, Ceratitis capitata (Diptera: Tephritidae). Annals of the Entomological Society of America, 96(3), 237-244 (2003).

34. Chang, C. L., Coudron, T. A., Goodman, C., Stanley, D., An, S., \& Song, Q. Wheat germ oil in larval diet influences gene expression in adult oriental fruit fly. Journal of Insect Physiology, 56(4), 356- 
365(2010).).

35. Cheng, D., Chen, L., Yi, C., Liang, G., \& Xu, Y. Association between changes in reproductive activity and D-glucose metabolism in the tephritid fruit fly, Bactrocera dorsalis (Hendel). Scientific reports, 4(1), 19 (2014).

36. Wicker-Thomas, C., Garrido, D., Bontonou, G., Napal, L., Mazuras, N., Denis, B., ... \& Montagne, J. Flexible origin of hydrocarbon/pheromone precursors in Drosophila melanogaster [S]. Journal of lipid research, 56(11), 2094-2101 (2015).

37. Parvy, J. P., Napal, L., Rubin, T., Poidevin, M., Perrin, L., Wicker-Thomas, C., \& Montagne, J. Drosophila melanogaster Acetyl-CoA-carboxylase sustains a fatty acid-dependent remote signal to waterproof the respiratory system. PLoS genetics, 8(8), e1002925. https://doi.org/10.1371/journal.pgen.1002925 (2012).

38. Sillam-Dussès, D., Hanus, R., Poulsen, M., Roy, V., Favier, M., \& Vasseur-Cognet, M. The role of the glucose-sensing transcription factor carbohydrate-responsive element-binding protein pathway in termite queen fertility. Open biology, 6(5), 160080 (2016).

39. Dallai, R., T Baldari, C., Marchini, D., de Filippis, T., Rosetto, M., \& Manetti, A. G. Juvenile hormone regulates the expression of the gene encoding ceratotoxin a, an antibacterial peptide from the female reproductive accessory glands of the medfly Ceratitis capitata. Journal of insect physiology, 43(12), 1161-1167. https://doi.org/10.1016/s0022-1910(97)00052-8 (1997).

40. Harwood, J. F., Chen, K., Müller, H. G., Wang, J. L., Vargas, R. I., \& Carey, J. R. Effects of diet and host access on fecundity and lifespan in two fruit fly species with different life-history patterns. Physiological entomology, 38(1), 81-88 (2013).

41. Romanyukha, A. A., Carey, J. R., Karkach, A. S., \& Yashin, A. I. The impact of diet switching on resource allocation to reproduction and longevity in Mediterranean fruit flies. Proceedings of the Royal Society of London. Series B: Biological Sciences, 271(1545), 1319-1324 (2004).

42. Hassan, B., Siddiqui, J. A., \& Xu, Y. Vertically Transmitted Gut Bacteria and Nutrition Influence the Immunity and Fitness of Bactrocera dorsalis Larvae. Frontiers in microbiology, 11, 596352. https://doi.org/10.3389/fmicb.2020.596352 (2020).

43. Povey, S., Cotter, S. C., Simpson, S. J., \& Wilson, K.. Dynamics of macronutrient self-medication and illness-induced anorexia in virally infected insects. Journal of Animal Ecology, 83(1), 245-255 (2014).

44. Lee, K. P., Simpson, S. J., Clissold, F. J., Brooks, R., Ballard, J. W. O., Taylor, P. W., ... \& Raubenheimer, D.. Lifespan and reproduction in Drosophila: new insights from nutritional geometry. Proceedings of the National Academy of Sciences, 105(7), 2498-2503 (2008).

45. Gomulski, L. M., Dimopoulos, G., Xi, Z., Scolari, F., Gabrieli, P., Siciliano, P., ... \& Gasperi, G. Transcriptome profiling of sexual maturation and mating in the Mediterranean fruit fly, Ceratitis capitata. PloS one, 7(1), e30857 (2012).

46. Donzelli, B. G., \& Krasnoff, S. B. Molecular Genetics of Secondary Chemistry in Metarhizium Fungi. Advances in genetics, 94, 365-436. https://doi.org/10.1016/bs.adgen.2016.01.005 (2016). 
47. Mc Namara, L., Dolan, S. K., Walsh, J., Stephens, J. C., Glare, T. R., Kavanagh, K., \& Griffin, C. T. Oosporein, an abundant metabolite in Beauveria caledonica, with a feedback induction mechanism and a role in insect virulence. Fungal biology, 123(8), 601-610 (2019).

48. Stączek, S., Zdybicka-Barabas, A., Pleszczyńska, M., Wiater, A., \& Cytryńska, M. Aspergillus niger a-1,3-glucan acts as a virulence factor by inhibiting the insect phenoloxidase system. Journal of invertebrate pathology, 171, 107341. https://doi.org/10.1016/j.jip.2020.107341 (2020).

49. Kaur, H. P., Singh, B., Thakur, A., Kaur, A., \& Kaur, S. Studies on immunomodulatory effect of endophytic fungus Alternaria alternata on Spodoptera litura. Journal of Asia-Pacific Entomology, 18(1), 67-75 (2015).

50. Valtierra-de-Luis, D., Villanueva, M., Caballero, J., Matas, I. M., Williams, T., \& Caballero, P. Quantification of dose-mortality responses in adult Diptera: Validation using Ceratitis capitata and Drosophila suzukii responses to spinosad. PloS one, 14(2), e0210545. https://doi.org/10.1371/journal.pone.0210545 (2019).

51. Mura, M. E., \& Ruiu, L.. Sex-Specific Sub-Lethal Effects and Immune Response in Ceratitis capitata Wied. (Diptera: Tephritidae) Challenged with Spinosad. Insects, 9(3), 73.

https://doi.org/10.3390/insects9030073 (2018).

52. Leulier, F., Rodriguez, A., Khush, R. S., Abrams, J. M., \& Lemaitre, B. The Drosophila caspase Dredd is required to resist Gram-negative bacterial infection. EMBO reports, 1(4), 353-358 (2000).

53. Meunier, N., Belgacem, Y. H., \& Martin, J. R. Regulation of feeding behaviour and locomotor activity by takeout in Drosophila. Journal of Experimental Biology, 210(8), 1424-1434 (2007).

54. So, W. V., Sarov-Blat, L., Kotarski, C. K., McDonald, M. J., Allada, R., \& Rosbash, M. Takeout, a novel Drosophila gene under circadian clock transcriptional regulation. Molecular and cellular biology, 20(18), 6935-6944 (2000).

55. Wijesekera, T. P., Saurabh, S., \& Dauwalder, B. Juvenile hormone is required in adult males for Drosophila courtship. PloS one, 11(3), e0151912 (2016).

56. Saurabh, S., Vanaphan, N., Wen, W., \& Dauwalder, B. High functional conservation of takeout family members in a courtship model system. Plos one, 13(9), e0204615 (2018).

57. Zhang, W., Liang, G., Ma, L., Jiang, T., \& Xiao, H. Dissecting the role of juvenile hormone binding protein in response to hormone and starvation in the cotton bollworm, Helicoverpa armigera (Hübner) (Lepidoptera: Noctuidae). Journal of economic entomology, 112(3), 1411-1417 (2019).

58. Peng, X., Wang, S., Huang, L., Su, S., \& Chen, M. Characterization of Rhopalosiphum padi takeout-like genes and their role in insecticide susceptibility. Pesticide Biochemistry and Physiology, 171, 104725 (2021).

59. Msaad Guerfali, M., Raies, A., Ben Salah, H., Loussaief, F., Caceres, C. Pilot Mediterranean fruit fly Ceratitis capitata rearing facility in Tunisia: constraints and prospects. In: Vreysen MJB, Robinson AS, Hendrichs J editors. Area-wide Control of Insect Pests: From Research to Field Implementation. Springer: Dordrecht, The Netherlands. p. 535-543 (2007). 
60. Msaad Guerfali, M., Djobbi, W., Charaabi, K., Hamden, H., Fadhl, S., Marzouki, W., Chevrier, C. Evaluation of Providencia rettgeri pathogenicity against laboratory Mediterranean fruit fly strain (Ceratitis capitata). Plos one. 13(5) (2018).

61. Warburg, M. S., \& Yuval, B. Effects of diet and activity on lipid levels of adult Mediterranean fruit flies. Physiological Entomology, 21(2), 151-158 (1996).

62. Tolmasky, D. S., \& Krisman, C. R. The degree of branching in (alpha 1, 4)-(alpha 1, 6)-linked glucopolysaccharides is dependent on intrinsic properties of the branching enzymes. European journal of biochemistry, 168(2), 393-397 (1987).

63. Baker, J. E., Woo, S. M., \& Byrd, R. V. Ultrastructural features of the gut of Sitophilus granarius (L.) (Coleoptera: Curculionidae) with notes on distribution of proteinases and amylases in crop and midgut. Canadian journal of zoology, 62(7), 1251-1259 (1984).

64. Peterson, G. L. A simplification of the protein assay method of Lowry et al. which is more generally applicable. Analytical biochemistry, 83(2), 346-356 (1977).

\section{Tables}

Table 1. Fecundity and Fertility parameters $( \pm \mathrm{SE})$ of $C$. capitata adults infected by $P$. lilacinum isolate.

\begin{tabular}{lll} 
& Fertility & Fecundity/fly \\
\hline$\square$ C X C & $91.7 \pm 2.7$ & $245 \pm 4$ \\
\hline$\square$ inf $\times$ inf & $28.8^{\star} \pm 4.4$ & $133.5 \pm 1.08$
\end{tabular}

$\left.{ }^{(}\right)$indicates a significant difference in the between infected adults and controls (1-way ANOVA, $p<0.05$ ).

Table 2. Variance Analysis table on Statut, Time, infection and infection variables interaction. 


\begin{tabular}{|c|c|c|c|c|c|c|c|}
\hline & $\begin{array}{l}\text { Attacin- } \\
\boldsymbol{A}\end{array}$ & $\begin{array}{l}\text { Ceratotoxin- } \\
A\end{array}$ & $\begin{array}{l}\text { Cecropin- } \\
1\end{array}$ & Defensin & Relish & $\begin{array}{l}\text { PGRP- } \\
L C\end{array}$ & Takeout \\
\hline Statut & $* * *$ & * & & & $* * *$ & & * \\
\hline Sex & $* * *$ & $* * *$ & & & & & $* * *$ \\
\hline Time & $* * *$ & $* * *$ & & ** & $* * *$ & & $* * *$ \\
\hline Infection & * & & & & & & $* * *$ \\
\hline Statut $x$ Sex & $* * *$ & * & & & ** & * & * \\
\hline Statut $\times$ Time & * & * & $* *$ & & & & $* * *$ \\
\hline Statut x Infection & * & & & & ** & & \\
\hline Sex $\times$ Time & $* * *$ & $* * *$ & & & & & $* * *$ \\
\hline Sex $x$ Infection & * & & & & & & $* * *$ \\
\hline Time $x$ Infection & * & & & & & & ** \\
\hline Statut $x$ Sex $x$ Time & * & * & & & & * & $* * *$ \\
\hline $\begin{array}{l}\text { Statut } x \text { Sex } x \\
\text { Infection }\end{array}$ & * & & & & ** & & \\
\hline $\begin{array}{l}\text { Sex } x \text { Time } x \\
\text { Infection }\end{array}$ & * & & & & & & * \\
\hline $\begin{array}{l}\text { Statut } x \text { Sex } x \text { Time } \\
\text { x Infection }\end{array}$ & $* *$ & & & & & & \\
\hline
\end{tabular}

Signification codes. ${ }^{*} p, 0.05,{ }^{* \star} p, \leq 0.01,{ }^{\star \star \star} p, \leq 0.001$. ANOVA test.

Figures 


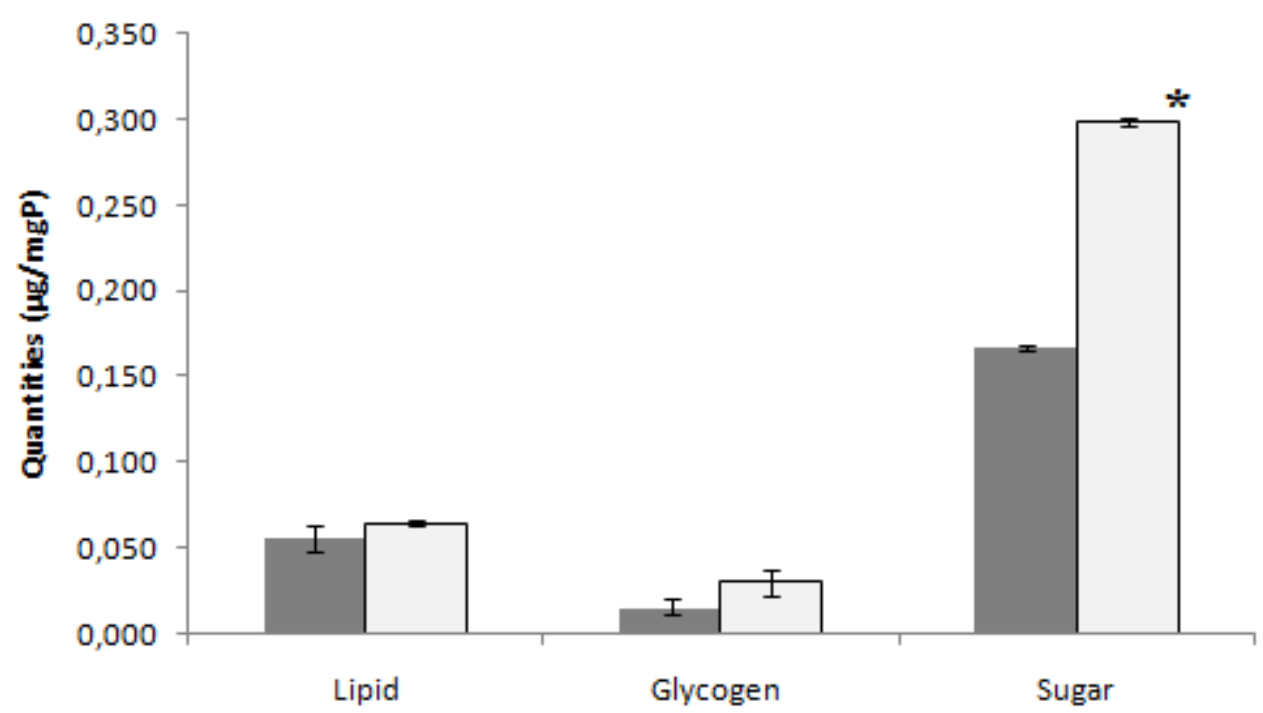

Figure 1

Average amounts of lipid, glycogen and sugar in infected larvae (white columns) and control larvae (black columns) of Mediterranean fruit flies C. capitata . Bars represent standard errors. $\left({ }^{*}\right)$ indicates significant difference between columns $(P<0.005)$.
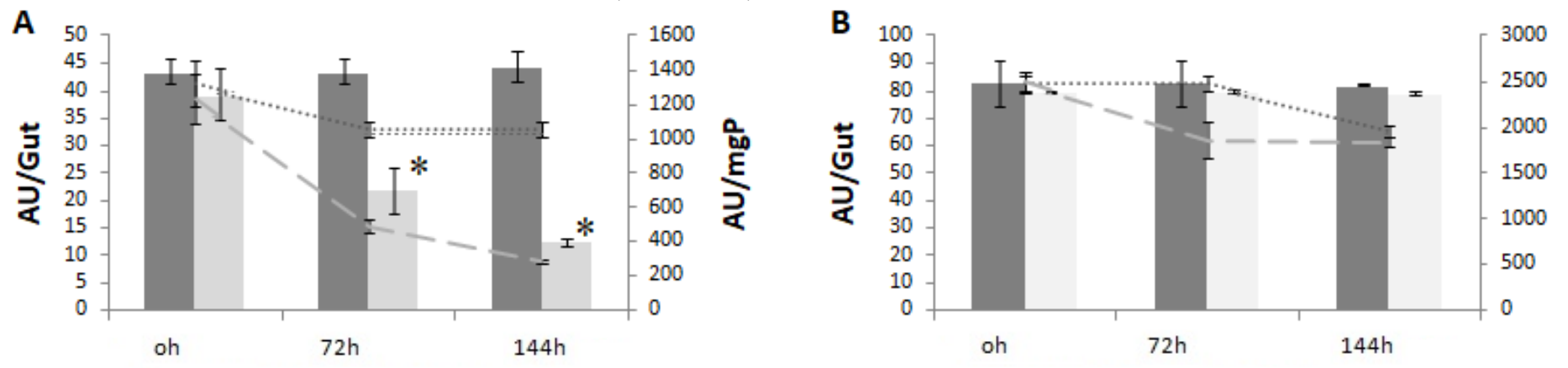

Hours post inoculation
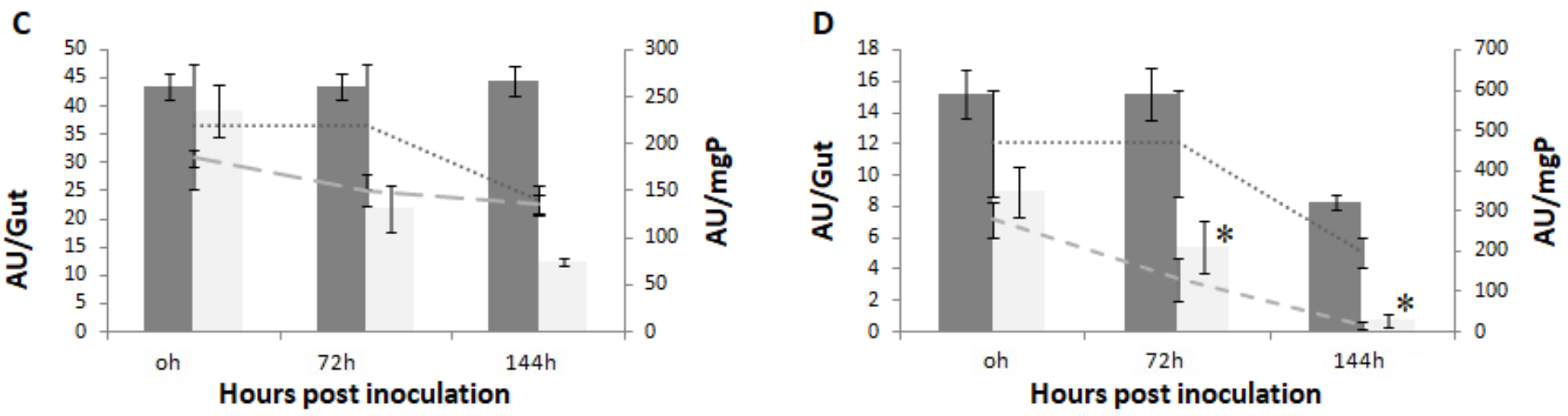

Figure 2

Digestive disaccharide and polysaccharide activities after fungal inoculation to Ceratitis capitata (24 to 144 hours post-inoculation); Black and Gray bars represent enzymatic activities per gut for control and infected flies respectively, (---) and (....) represent enzymatic activities per mg protein for control and 
infected flies respectively. (A) rep-resent enzymatic activities on Starch; (B) represent enzymatic activities on maltose (C) represent enzymatic activities on sucrose; (D) represent enzymatic activities on Pec-tin. Bars represent standard errors. $\left.{ }^{*}\right)$ indicates significant difference between control and infected flies $(P<$ 0.05).

\section{Figure 3}

Digestive glycosyl hydrolase activities after fungal inoculation to C. capitata (24 to 144 hours postinoculation). Black and Gray bars represent glycosyl hydrolase activities per gut for control and infected flies respectively, (---) and (....) represent glycosyl hydrolase activities per mg protein for control and infected flies respectively. (A) $\beta$-galactosidase activities; (B) a-glucosidase activities; (C) a-galactosidase activities and (D) $\beta$-glucosidase activities. Substrates used: PNPaglu, PNPbglu, PNPagal, PNPbgal. Bars represent standard errors. $\left(^{*}\right)$ indicates significant difference between control and infected flies $(P<0.05)$.

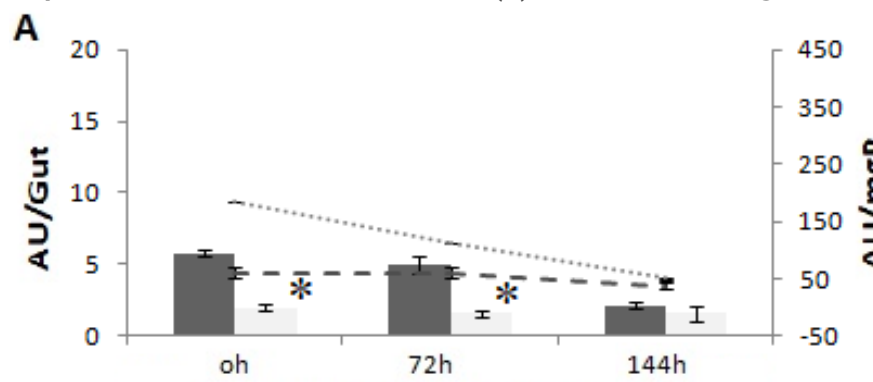

Hours post inoculation
B

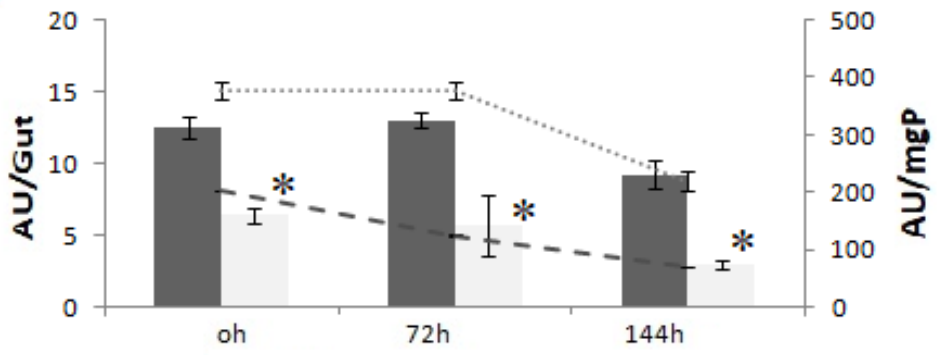

Hours post inocultion

\section{Figure 4}

Digestive proteinase activities after fungal inoculation to C. capitata (24 to 144 hours post-inoculation). (A) Dark bars represent azocaseinolytic activities per gut for control flies; gray bars represent azocaseinolytic activities per gut for infected flies; (- - ) represent azocaseinolytic activities per mg protein for control flies; (....) represent azo-caseinolytic activities per mg protein for infected flies. (B) Dark bars represent hemoglobinasic activities per gut for control flies; gray bars represent hemoglobinasic activ-ities per gut for infected flies; (- - ) represent hemoglobinasic activities per mg protein for control flies; (....) represent hemoglobinasic activities per mg protein for infect-ed flies. Bars represent standard errors. $\left(^{\star}\right)$ indicates significant difference between control and infected flies $(P<0.05)$. 

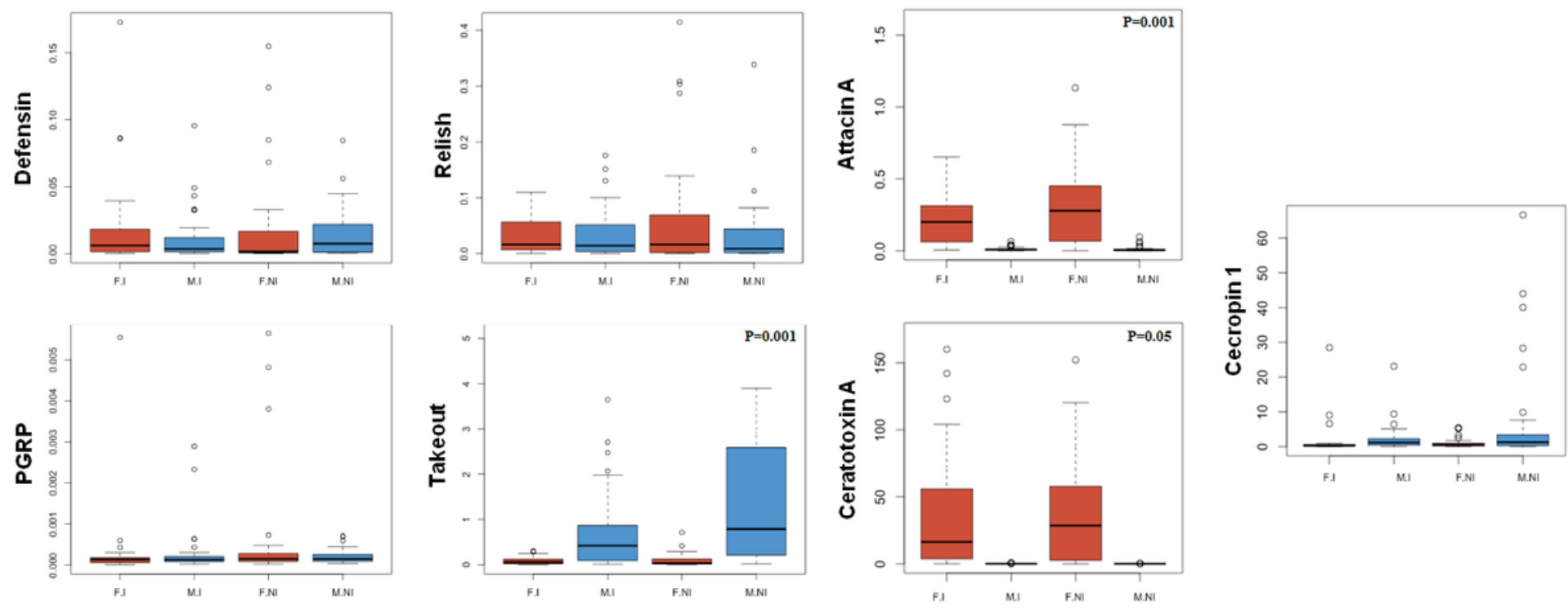

Figure 5

Characteristics of transcript levels for 7 immune genes in C. capitata inoculated with P. lilacinum. Red boxplot: females; blue boxplot: males; M.I: male inoculated; FI: female inoculated; M.NI: male not inoculated; .NI: female not inoculated. Each value is plotted as a dot. boxplots represent 3 independent biological replicates, pvalues are reported topleft on each panels when signif-icant (ANOVA F-test).
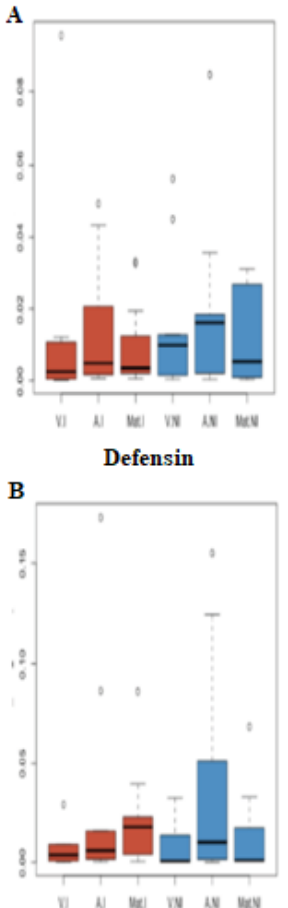

Defensin

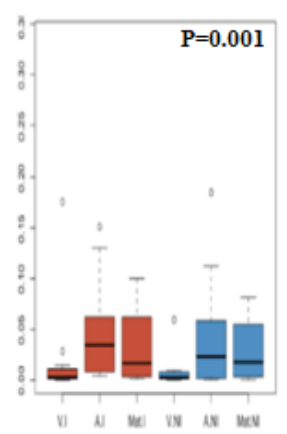

Relish

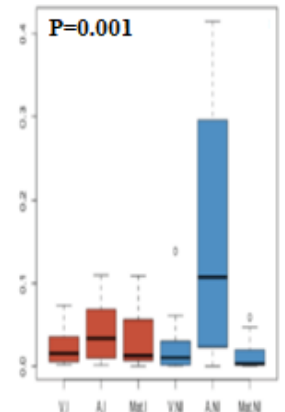

Relish
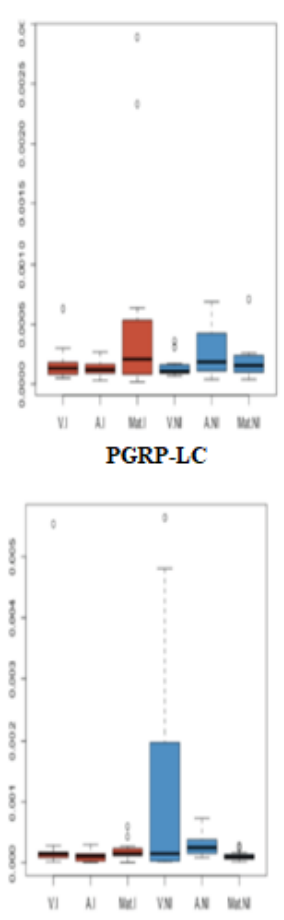

PGRP-LC
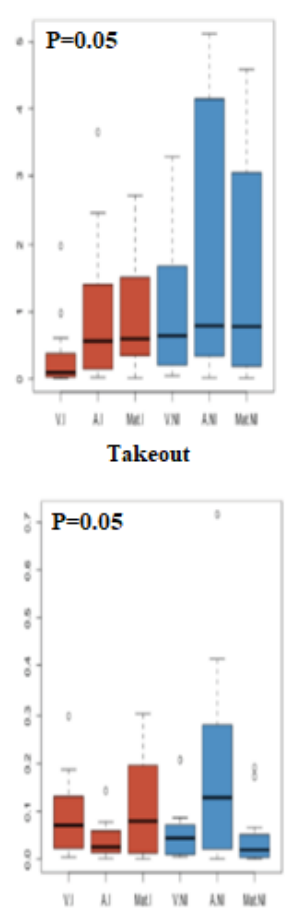

Takeout

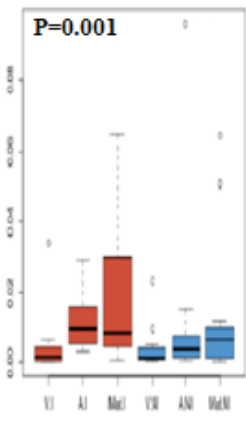

Attacin-A

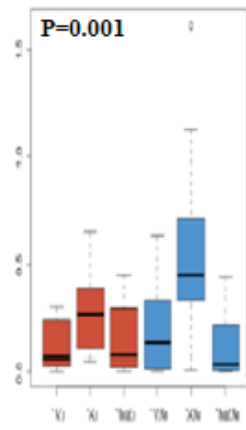

Attacin-A
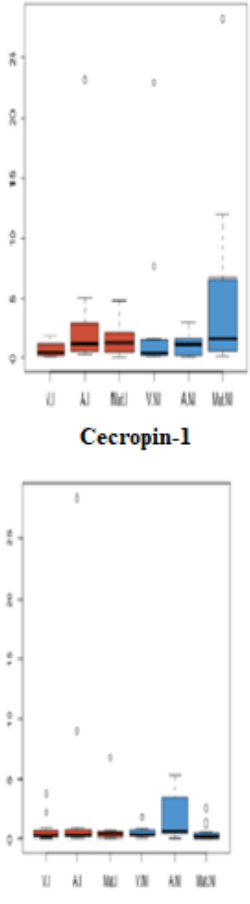

Cecropin-1
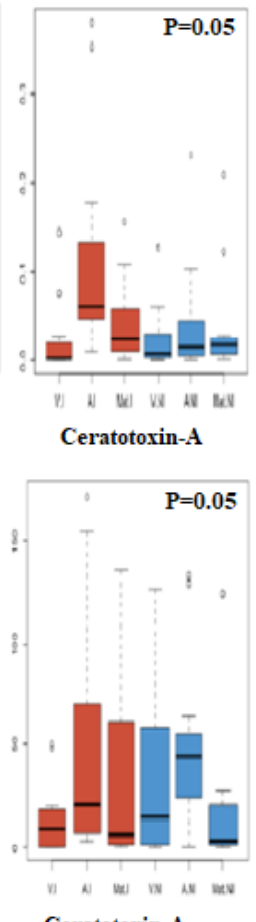

Figure 6

Characteristics of transcript levels for 7 immune genes in C. capitata inoculated with P. lilacinum based on status and infection variables. (a) transcript levels of immune genes in C. capitata males; (b): transcript levels of immune genes in C. capitata females. Red boxplot: inoculated flies; blue boxplot: 
control flies; V.I: Virgin inoculated; A.I: Mated inoculated; Mat.I: mature inoc-ulated; V.IN: Virgin not inoculated ; A.NI: Mated not inoculated; Mat.NI: mature not inoculated. Each value is plotted as a dot. boxplots represent 3 independent biological replicates, pvalues are reported topleft on each panels when significant (ANOVA F-test).

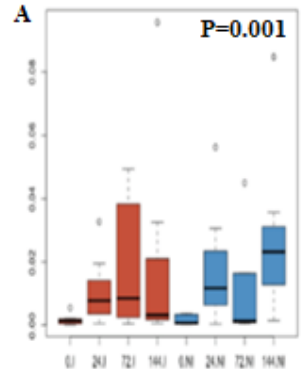

B

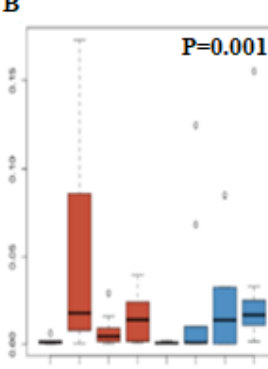

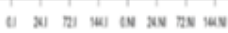

Defensin

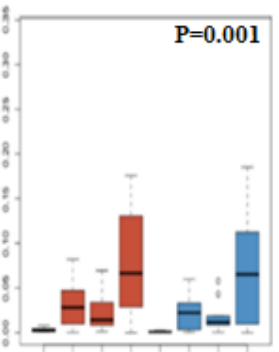

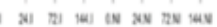
Relish

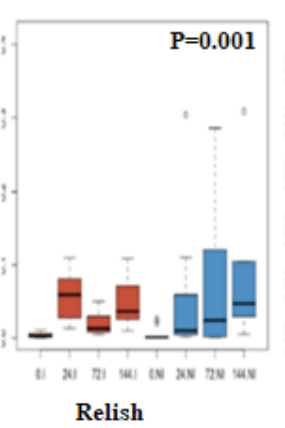

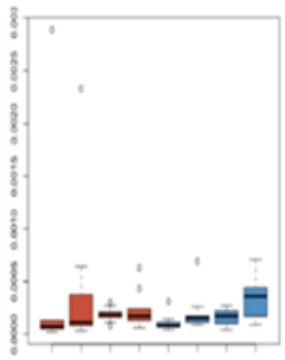

PGRP-LC

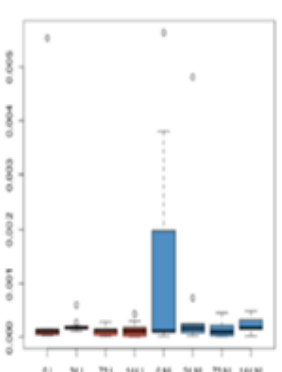

PGRP-LC

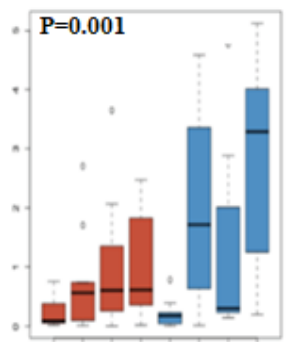

Takeout

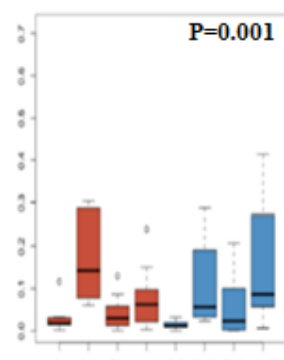

Takeout

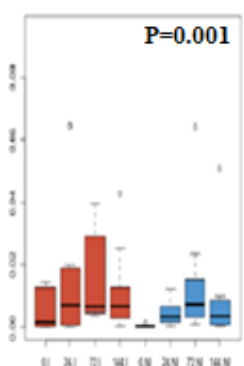

Attacin-A

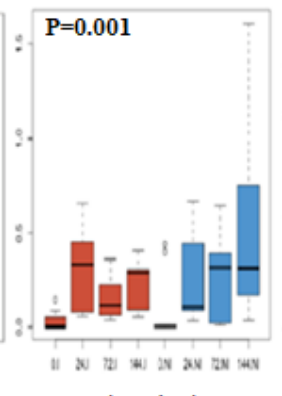

Attacin-A

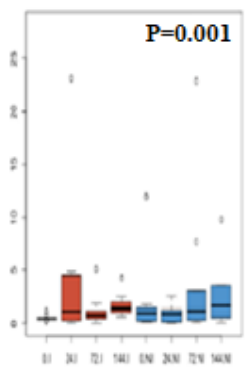

Cecropin-1

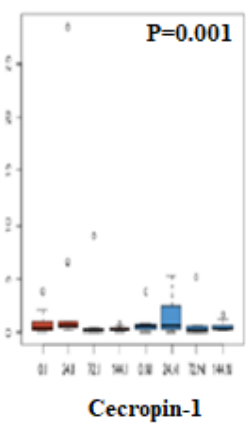

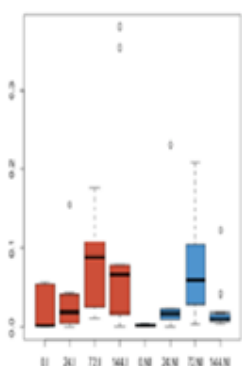

Ceratotoxin-A

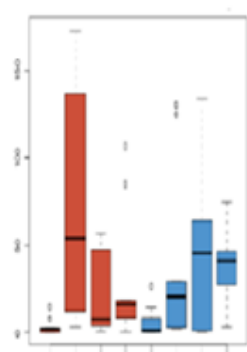

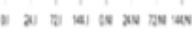

Ceratotoxin-A

\section{Figure 7}

Characteristics of transcript levels for 7 immune genes in C. capitata inoculated with P. lilacinum based on times variable. (A) transcript levels of immune genes in C. capitata males; (B): tran-script levels of immune genes in C. capitata females. Red boxplot: inoculated flies; blue boxplot: control flies; $0.1: 0 \mathrm{~h}$ after inoculation; 24.I: 0 24h after inoculation; 72.I: 72h after inoculation ; 144.I: 144h after inoculation, Each value is plotted as a dot. boxplots represent 3 independent biological replicates. Each value is plotted as a dot. boxplots represent 3 independent biological replicates, pvalues are reported topleft on each panels when significant (ANOVA F-test). 


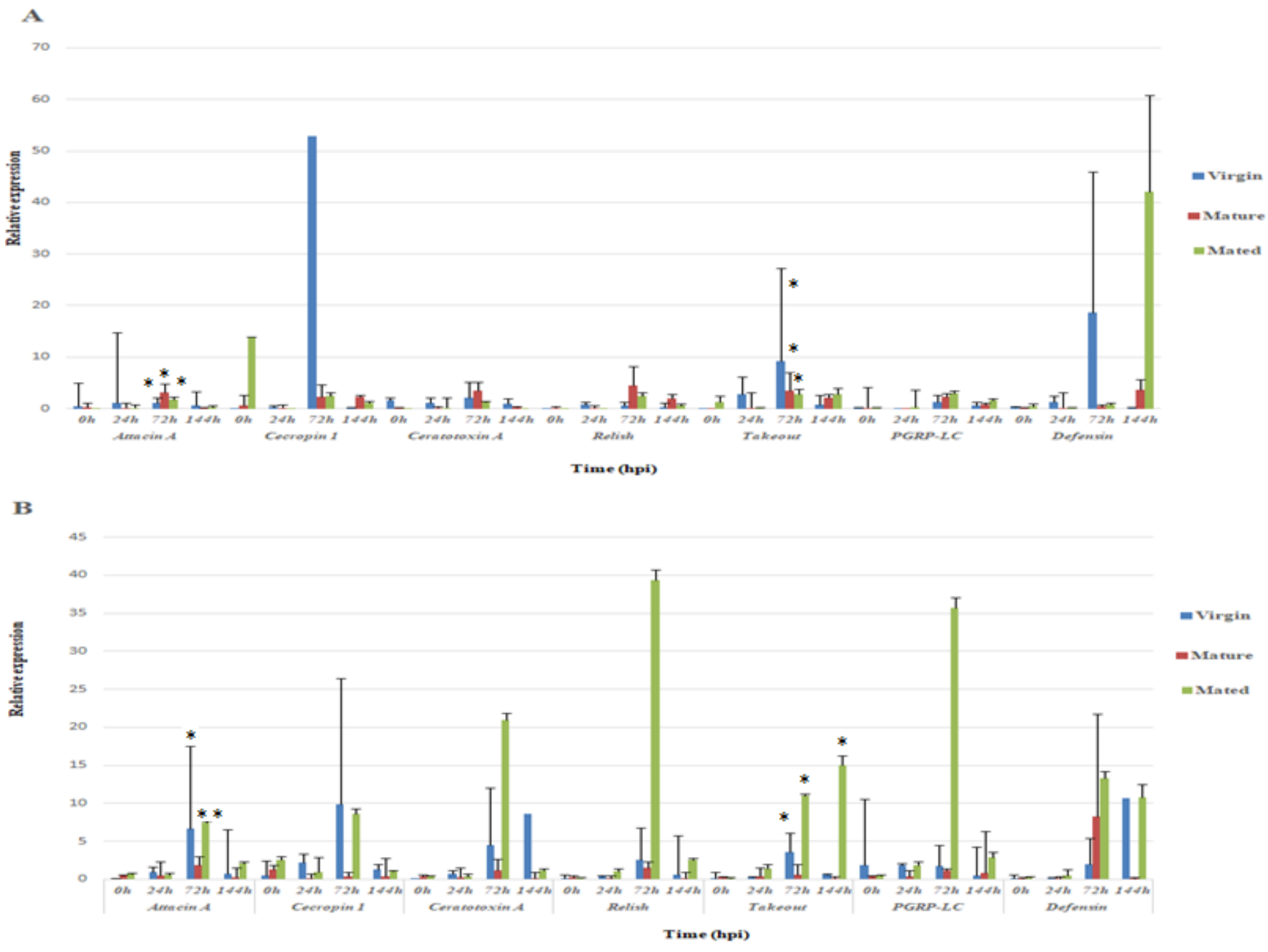

Figure 8

Characteristics of transcript levels for 7 immune genes in C. capitata inoculated with P. lilacinum. . qPCR analysis of expression levels of AMPs in the (A) males and (B) Females of inoculated at 0, 24, 72 and 144 hpi (hours post inoculation). Three biological replicates were conducted. Error bars indicate SD. Asterisks above bars indicate for each gene a significant difference with untreated control (ANOVA, Tukey adjusted $p<0.05)$.

\section{Supplementary Files}

This is a list of supplementary files associated with this preprint. Click to download.

- TableS1.doc 